\title{
The State of Aggregation of $\alpha$-Crystallin Detected after Large-Scale Preparation by Zonal Centrifugation
}

\author{
Hans Blokmendal, Ton Berns, Anneke Zweers, Herman Hoenders, and Ennio L. Benedetti \\ Laboratorium voor Biochemie der Universiteit, Nijmegen
}

(Received June 17/October 22, 1971)

\begin{abstract}
The protein $\alpha$-crystallin from calf eye lenses can be isolated in very high yield by zonal centrifugation. No other purification steps are required in order to obtain preparations the purity criteria of which allow sequence studies after dissociation into polypeptide chains. By this method evidence is provided that $\alpha$-crystallin is a population of aggregates built up by four different polypeptide chains, occurring in an almost constant ratio independent on the size of the aggregate.
\end{abstract}

The possibility to fractionate lens proteins by electrophoretic techniques has been reviewed previously [1]. It appeared that with exception of isofocusing and free continuous electrophoresis all known electrophoretic procedures had been applied. Meanwhile the two latter methods have also been reported [2-4]. In most electrophoretic isolation procedures the yield of purified protein is moderate. However, for the study on the primary structure of lens proteins which has recently been started [5-8] rather large quantities of highly purified material are required. We have demonstrated earlier [9] that $\alpha$-crystallin could be isolated by ultracentrifugation in a swinging bucket rotor. Also in this method the yield was not very high.

In the present paper we show that $\alpha$-crystallin in a highly purified state and in large yield can be isolated by zonal centrifugation as sole purification step. A second advantage of this method is that partial purification for the other water-soluble lens proteins is achieved.

Part of this work has been communicated at the International Lens Symposium (Utrecht 1971).

\section{MATERIALS AND METHODS}

\section{Lens Extract}

The mixture of water-soluble proteins from calf lens tissue was isolated as described earlier [10].

\section{Zonal Centrifugation}

Zonal centrifugation was carried out in a B-XXIX rotor of an IEC ultracentrifuge. The total volume was $1440 \mathrm{ml}$. As we observed in a test run that the $\alpha$-crystallin fraction sedimented in a range from $16 \mathrm{~S}$ to about $25 \mathrm{~S}$ we devised a gradient in which zone sharpening only for $\alpha$-crystallin would occur.
This gradient is represented graphically in Fig. 1 Centrifugation was performed at $35000 \mathrm{rev}$. $/ \mathrm{min}$ fo $14 \mathrm{~h}$ and at $8^{\circ} \mathrm{C}$. All sucrose solutions containe $0.05 \mathrm{M}$ Tris-HCl at $\mathrm{pH}$ 7.6. The sample $(2.5 \mathrm{~g}$ protein was pumped into the rotor as an inverse gradient is a volume of $70-100 \mathrm{ml}$. The rotor was emptied b. pumping in $60 \%(\mathrm{w} / \mathrm{w})$ sucrose solution at $30 \mathrm{ml}$ min. The absorbance was measured automatically a $280 \mathrm{~nm}$ in a Gilford spectrophotometer, adapted wit] an IEC 2-mm flow cell. The separated fractions wer dialyzed against distilled water and lyophilized.

\section{Immunoelectrophoresis}

Antibodies to total water-soluble lens protein were isolated from hyperimmunized white $\mathrm{Nev}$ Zealand rabbits. Immunoelectrophoresis was carriec out according to the micro-modification of Schei degger [11] using LKB apparatus. The gels werı

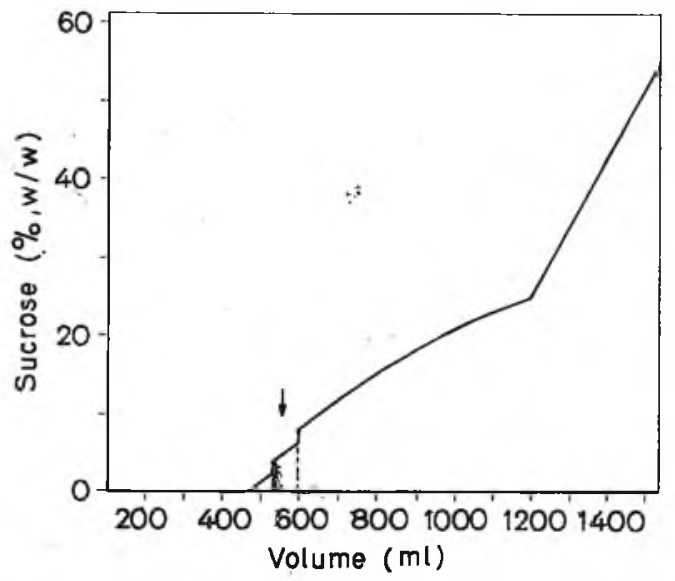

Fig. 1. Graphical representation of the gradient for zone centrifu gation of bovine-lens proteins. The sample was applied in a] inverse gradient (hatched area) 
stained for $15 \mathrm{~min}$ in $0.1 \%$ Sudan black dissolved in $2 \%$ acetic acid. The staining was performed in $2 \%$ acetic acid to which $2 \%$ glycerol was added.

\section{Amino-Acid Analysis}

Protein samples were hydrolyzed in $6 \mathrm{~N} \mathrm{HCl}$ (Merck, Suprapur) at $110^{\circ} \mathrm{C}$ for $22 \mathrm{~h}$ in evacuated sealed Pyrex tubes. The subsequent analyses were carried out with a Phoenix amino acid analyser, equipped with micro-cuvettes (optical path 10 and $15 \mathrm{~mm}$ ) and an Infotronics model CRS-10AB2 integrator. The apparatus was automated as described. by Gerding [12]. Calibration runs were carried out with Beckman amino acid calibration mixtures $(2.5 \mu \mathrm{mol} / \mathrm{ml}$ of each amino acid). Some protein preparations were hydrolyzed during varying times in order to determine the following correction factors for certain amino acids: threonine $3 \%$, serine $10 \%$, valine $5 \%$, isoleucine $2 \%$.

\section{Sedimentation Analysis}

Sedimentation velocity experiments were performed in a Beckman Spinco model $\mathbf{E}$ analytical ultracentrifuge using ultraviolet absorption optics $(280 \mathrm{~nm})$ in combination with an automatic scanner as described by van Es and Bont [13]. The solvent was $0.05 \mathrm{M}$ Tris-HCl buffer $\mathrm{pH}$ 7.6. Protein concentrations were in the order of magnitude of $1 \mathrm{mg} / \mathrm{ml}$. The absence of sucrose after dialysis was checked by means of refractive index determinations. Runs were made at 53000 to $68000 \mathrm{rev} . / \mathrm{min}$ at about $20^{\circ} \mathrm{C}$. Sedimentation coefficients were corrected to water at $20^{\circ} \mathrm{C}\left(s_{20, w}\right)$.

\section{Gel Electrophoresis in 6-M Urea}

Electrophoresis was performed in polyacrylamide gels containing $6 \mathrm{M}$ urea, $\mathrm{pH} 8.9$ according to Bloemendal [14]. Protein samples $(50 \mu \mathrm{g})$ were dissolved in $20 \mu \mathrm{l}$ of $6 \mathrm{M}$ urea-Tris-EDTA-boric acid buffer at pH 8.9. In order to obtain optimal resolution of zones the run was performed in $10-\mathrm{cm}$ tubes for $150 \mathrm{~min}$ at $3.5 \mathrm{~mA}$ per tube.

\section{Electron Microscopy}

The electron microscopical investigation was performed using fraction 7 and fraction 11 of $\alpha$-crystallin. Observations were made at $\mathrm{pH}$ 7.8. Samples containing $1 \mu \mathrm{g} / \mathrm{ml} \quad 0.001 \mathrm{M}$ ammonium formate were spread on carbon grids and shadowed with carbon and platinum. Electron micrographs have been taken with the EM-300 Philips operating at $60 \mathrm{kV}$. used.

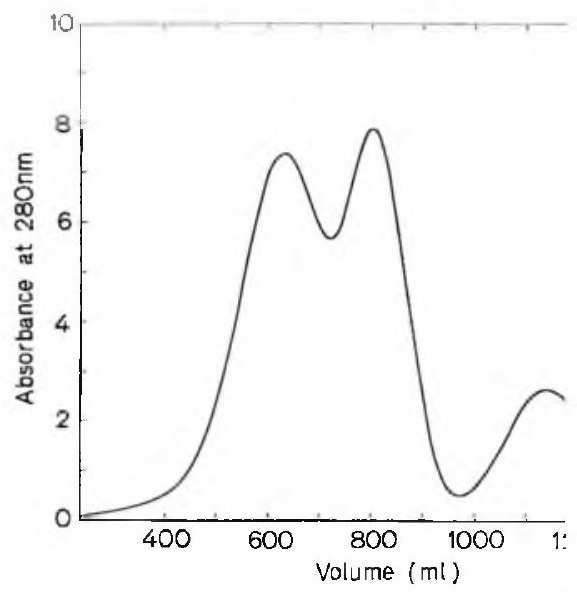

Fig.2. Sedimentation pattern of a typical run ? trifuge of bovine-lens proteins. Centrifugation at $35000 \mathrm{rev} . / \mathrm{min}$ for $14 \mathrm{~h} ; 2.5 \mathrm{~g}$ water solub was applied

Table 1. Fractions after zone centrifugation of $w$ proteins

The amount of protein was determined by we lysed and lyophilized material

\begin{tabular}{cc}
\hline Fraction no. & Volume \\
\hline & ml \\
1 & $500-600$ \\
2 & $600-700$ \\
3 & $700-800$ \\
4 & $800-900$ \\
5 & $900-970$ \\
6 & $970-1040$ \\
$7^{\mathrm{a}}$ & $1040-1100$ \\
$8^{\mathrm{a}}$ & $1100-1200$ \\
$9^{\mathrm{a}}$ & $1200-1300$ \\
$10^{\mathrm{a}}$ & $1300-1350$ \\
$11^{\mathrm{a}}$ & $1350-1420$ \\
\hline
\end{tabular}

a Immuno-electrophoretic analysis (compare Fig fraction 7-11 contained $\alpha$-crystallin freed from the proteins.

\section{RESULTS AND DISCUSSION}

In Fig. 2 the sedimentation pattern soluble lens proteins after zonal cent shown. A clear-cut separation between $(1000-1400 \mathrm{ml})$ and the other water proteins is obtained. Fractions wert listed in Table 1. Immunoelectropho ments revealed that fractions 1,2 a mixtures of so-called pre- $\alpha$-crystallin. and the $\beta$-crystallins. Fraction 4, how to contain only $\beta$-crystallins. From fra some overlap of $\beta$ and $\alpha$ occurs. In $f$ 10 and 11 only one precipitation arc car in the position characteristic for $\alpha$-crys 


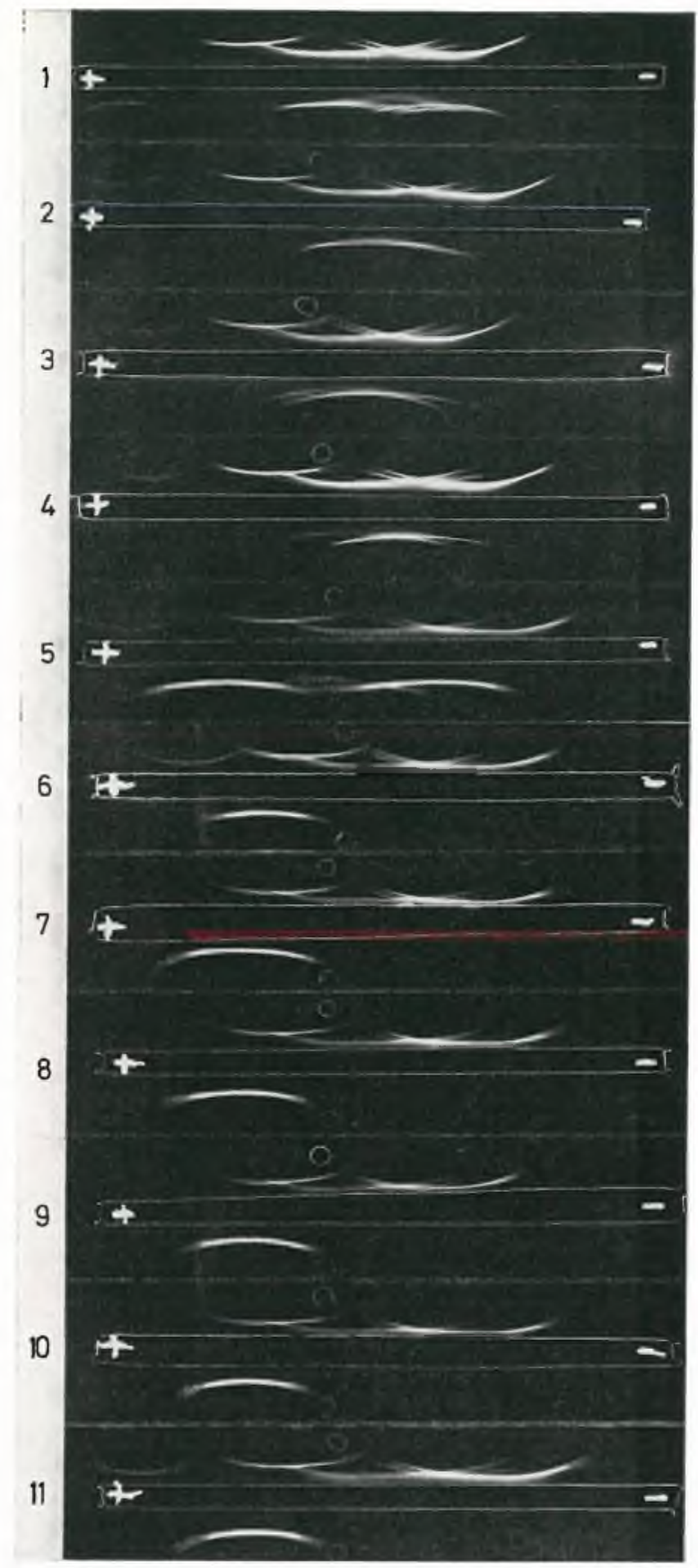

Fig. 3. Immunoelectrophoretic characterization of protein fractions separated by zonal centrifugation. 1-11 are the fractions as listed in Table 1. Per hole $2 \mu \mathrm{l}$ of $5 \%$ protein solution was applied. As reference $2 \mu l$ of $5 \%$ total water-soluble lens protein was electrophoresed parallel to each sample. Electrophoresis was performed at $6 \mathrm{~V} / \mathrm{cm}$ and $4 \mathrm{~mA}$ per slide for $3 \mathrm{~h}$. Slides 1-11 were developed with antiserum against total water-soluble lens protein for $16 \mathrm{~h}$

Hence it can be concluded that these fractions contain highly purified $\alpha$-crystallin. This conclusion obtained further support by other criteria. Com-

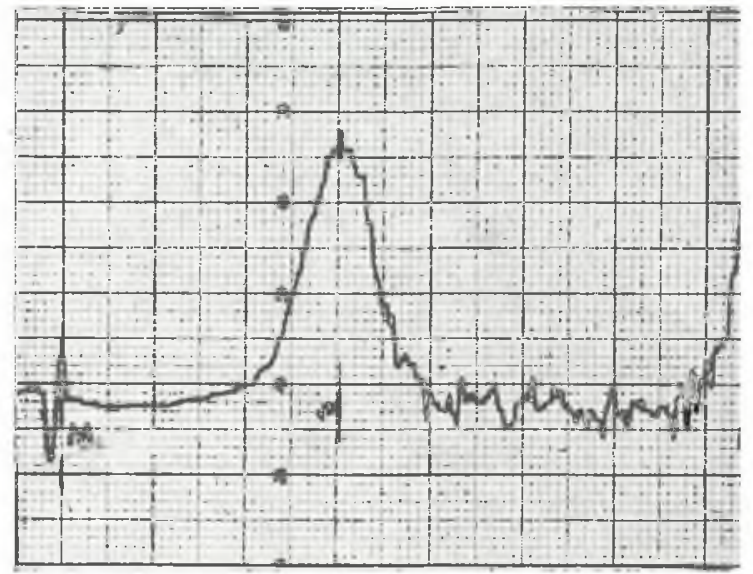

Fig.4. Sedimentation characteristics of $\alpha$-crystallin (fraction This recording of the differentiated absorbance was tra $8 \mathrm{~min}$ after reaching maximum speed (59780 rev./m $\mathbf{M}=$ meniscus; $\mathbf{B}=$ bottom

parison of the amino acid composition of the vari fractions reveals that from fractions 7 to 11 amino acid composition is similar whereas fraction and 4 as expected are quite different (Table 2). I difference between the two latter fractions and th from the $\alpha$-crsytallin region is more clearly dem strated by the electrophoretic experiments which r be discussed later on (Fig. 7).

One may ask why in a zonal centrifuge in wh band sharpening occurs $\alpha$-crystallin does not app as one sharp peak. In order to answer this quest we investigated the separated fractions in analytical ultracentrifuge. The sedimentation efficients of the different fractions are listed Table 3. From this table it can be seen that " $\alpha$-crystallin" fractions actually represent differ: aggregates. (A typical scanning pattern is sho in Fig.4.) Electron microscopic observation of different " $\alpha$-fractions" are in agreement with $t$ finding. Fig. 5 B shows that fraction $7(16.8 \mathrm{~S})$ c sists of aggregates displaying a great variety sizes ranging from 5 to $18 \mathrm{~nm}$. On the contrary aggregates in fraction 11 (24.4 S) have an alm uniform size with mean value of $20 \mathrm{~nm}$ (Fig.5 The histogram illustrates a comparative size distril tion for both fractions 7 and 11 (Fig.6). Mic heterogeneity of $\alpha$-crystaliin has already bf postulated by van Dam [17].

The nature and meaning of these aggrega still remain obscure. We have earlier shown t] $\alpha$-crystallin is composed of fo ur different polypept chains, designated $A_{1}, A_{2}, B_{1}$ and $B_{2}$ (A stands acidic and $B$ for basic) $[6,16]$. One might specul that the aggregates differ in quantity and type polypeptide chains. Evidence against this assumpt: was obtained by a series of elec trophoretic experime 
Table 2. Amino-acid composition of zonal-centrifuge fractions

\begin{tabular}{|c|c|c|c|c|c|c|c|c|}
\hline Amino-acid & 1 & 4 & 6 & 7 & 8 & 9 & 10 & 11 \\
\hline & \multicolumn{8}{|c|}{$\mathrm{mol} / 100 \mathrm{~mol}$} \\
\hline Aspartic & 11.5 & 8.4 & 10.0 & 8.7 & 9.3 & 8.6 & 8.8 & 9.8 \\
\hline Threonine & 3.7 & 3.3 & 3.8 & 3.2 & 3.3 & 3.6 & 3.4 & 3.8 \\
\hline Serine & 7.8 & 8.2 & 11.0 & 11.2 & 10.9 & 10.7 & 10.8 & 10.9 \\
\hline Glutamic & 14.6 & 15.5 & 11.6 & 10.2 & 11.1 & 10.6 & 10.0 & 11.1 \\
\hline Proline & 5.7 & 7.3 & 6.7 & 8.6 & 8.0 & 7.4 & 7.8 & 7.3 \\
\hline Glycine & 9.8 & 10.8 & 7.0 & 6.1 & 6.1 & 6.6 & 6.1 & 6.6 \\
\hline Alanine & 4.8 & 7.0 & 5.5 & 4.6 & 5.0 & 5.0 & 4.7 & 5.0 \\
\hline Valine & 5.5 & 7.1 & 5.7 & 6.1 & 7.2 & 6.2 & 6.6 & 8.1 \\
\hline Methionine & 2.1 & 1.4 & 1.0 & 1.1 & 1.4 & 1.0 & 1.3 & 1.0 \\
\hline Isoleucine & 3.2 & 3.0 & 4.5 & 4.8 & 4.6 & 4.8 & 5.0 & 4.3 \\
\hline Leucine & 6.7 & 4.9 & 7.4 & 8.0 & 7.9 & 7.9 & 8.4 & 7.6 \\
\hline Tyrosine & 5.4 & 3.4 & 3.0 & 2.9 & 2.6 & 2.5 & 2.9 & 2.4 \\
\hline Pȟnenylalanine & 4.2 & 5.1 & 6.7 & 7.8 & 7.9 & 7.7 & 8.1 & 6.8 \\
\hline Lysine & 4.0 & 4.5 & 4.4 & 4.5 & 4.3 & 5.1 & 4.6 & 4.5 \\
\hline Histidine & 3.2 & 3.5 & 4.0 & 4.4 & 4.0 & 4.5 & 4.3 & 4.0 \\
\hline Arginine & 7.2 & 6.7 & 7.8 & 7.8 & 7.5 & 8.0 & 7.5 & 7.1 \\
\hline
\end{tabular}

a Amino-acid composition as reported by Schoenmakers et al. [15].

Table 3. Sedimentation analysis of zonal-centrifuge fractions

\begin{tabular}{ccc}
\hline $\begin{array}{c}\text { Fraction } \\
\text { number }\end{array}$ & Protein type & $\begin{array}{c}\text { Sedimentation } \\
\text { coefficient }\end{array}$ \\
\hline & & $\mathrm{S}$ \\
4 & $\beta$-crystallin & 10.3 \\
7 & $\alpha$-crystallin & 16.8 \\
8 & $\alpha$-crystallin & 19.3 \\
9 & $\alpha$-crystallin & 21.1 \\
10 & $\alpha$-crystallin & 22.6 \\
11 & o-crystallin & 24.4 \\
\hline
\end{tabular}

with isolated aggregates. The isolated fractions were run in polyacrylamide gels containing $6 \mathrm{M}$ urea (Fig.7). Under this condition dissociation into the individual polypeptides occurs. Visual examination reveals immediately that each aggregate yields the same kinds of polypeptides. Tracings of the electrophoretic patterns and estimation of the percentages of $A_{1}, A_{2}, B_{1}$ and $B_{2}$ by planimetry (compare Fig. 8) revealed that the major component $A_{2}$ occurs in a constant percentage of $43 \% \pm 2 \%$, whereas there seems to be a slight increase of the amount of the "minor" chains ( $\mathbf{A}_{1}$ and $\mathbf{B}_{1}$, Table 4). Therefore the state of aggregation of $\alpha$-crystallin should be interpreted in terms of differences in the total number of composing polypeptides, rather than in marked differences in ratios of the individual polypeptide chains. At any rate the finding that there is no detectable chemical or immunological difference in the various size classes allows pooling of all $\alpha$-fractions to serve as pure starting material for the preparation of the individual polypeptides and subsequent structural studies.

Furthermore, zone centrifugation elucidates the question of the discrepancies in molecular weights which have been reported in the literature. These
Table 4. Comparison of the amount of polypeptides in the different size-classes of $\alpha$-crystall These data were obtained from duplicate exper two separate zonal runs. The maximal deviation vidual values obtained by planimetry $w$.

\begin{tabular}{ccc}
\hline Fraction & $\frac{\alpha \mathbf{A}_{1}(100)}{\alpha \mathbf{A}_{1}+\alpha \mathbf{A}_{8}}$ & $\frac{\alpha I}{\alpha \mathbf{B}}$ \\
\hline 7 & 30 \\
8 & 30 \\
9 & 34 \\
10 & 34 \\
11 & 36 & \\
\hline
\end{tabular}

values vary between 500000 and 1300001 highest values have consistently been foul scattering, whereas the "average" value derived from analytical ultracentrifuge ments. These discrepancies are now unde Only the light scattering method is sensiti tively small amounts of highly aggregated view of our experiments we conclude that o is a population of various aggregates whic up by the same basic and acidic polypept In this connection it might be misleading "subunits" of $\alpha$-crystallin rather than spea polypeptide chain composition.

It is tempting to speculate that the of aggregates of increasing size may be some molecular process during lens fiber ، tion, a process which continues from the state throughout the entire life cycle. Cons this view is the observation of Delcour constantinou [19] that differentiation of cells into lens fibers is characterized by a the relative polypeptide chain comp $\alpha$-crystallin. 

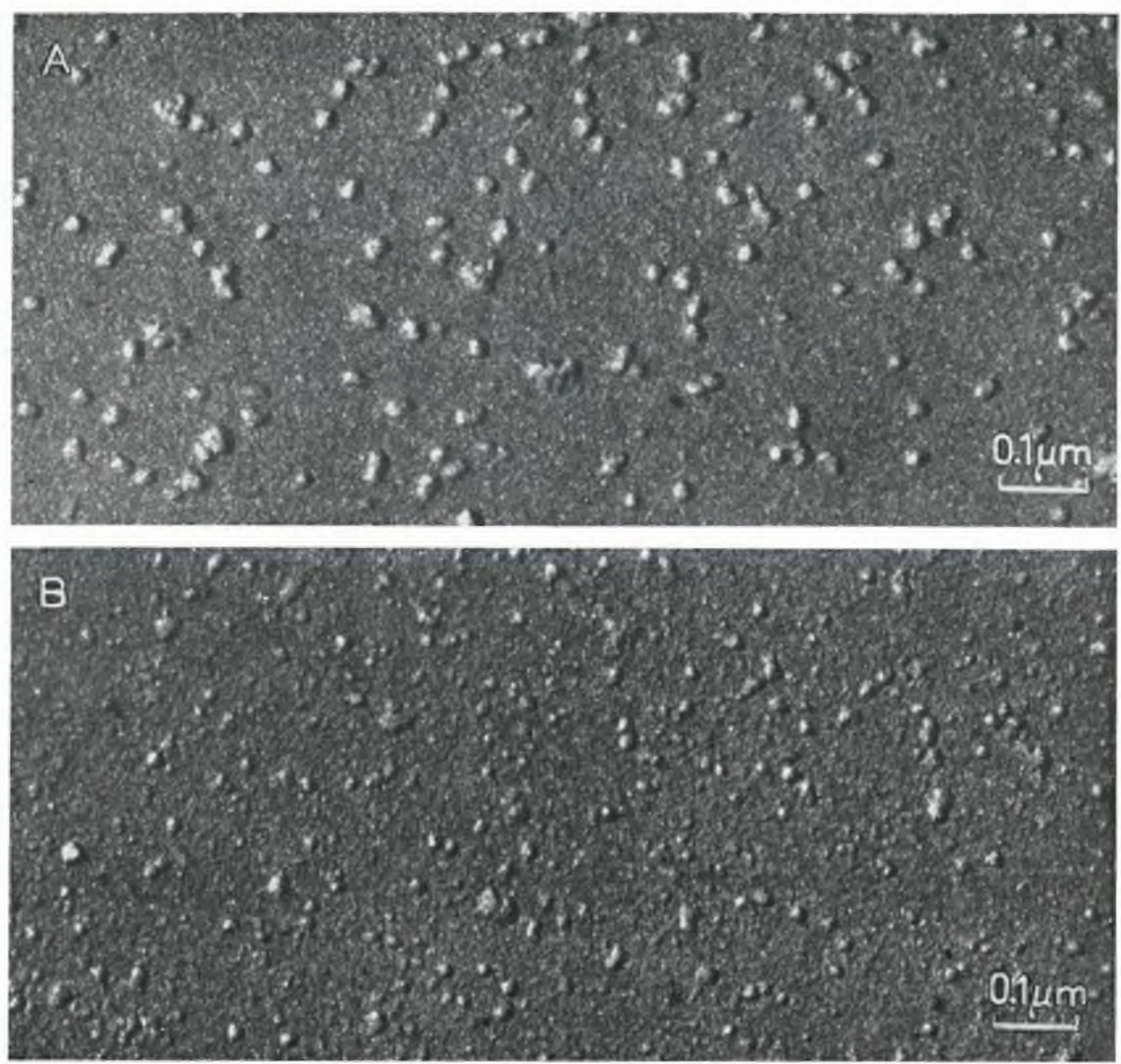

Fig.5. Electron micrograph of fractions of $\alpha$-crystallin. (A) Fraction 11 with sedimentation coefficient $24.4 \mathrm{~S}$; (B) fractio with sedimentation coefficient $16.8 \mathrm{~S}$

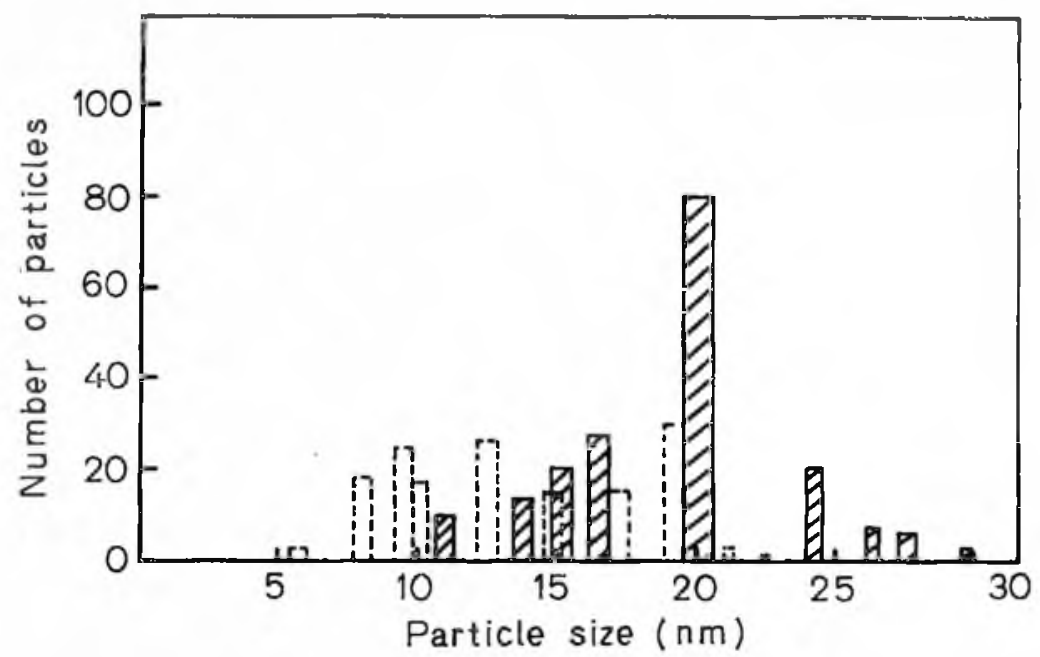

Fig.6. Size distribution of particles in fraction 7 (open blocks) and fraction 11 (hatched blocks) from a-crystallin purified zonal centrifugation 


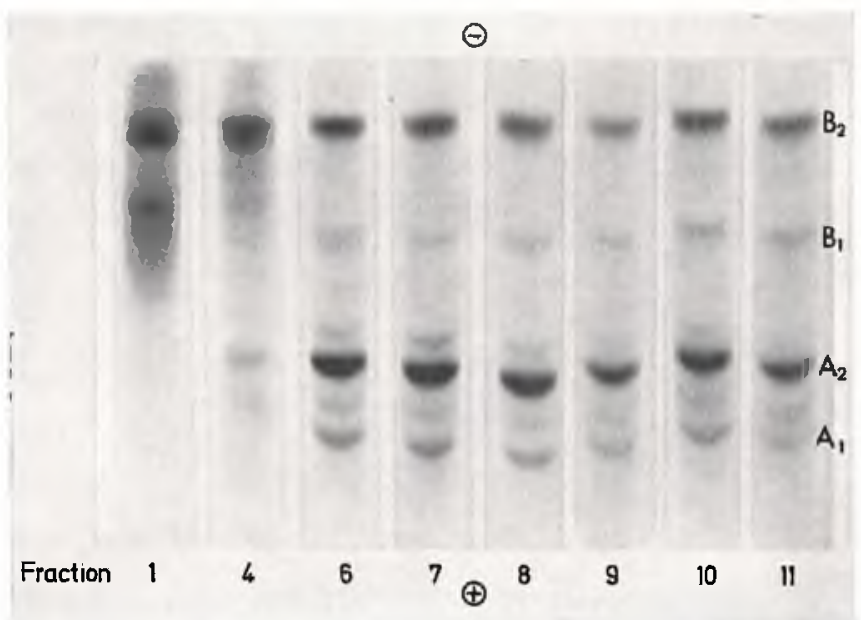

Fig.7. Polyacrylamide-gel electrophoresis of lens proteins in $6 M$ urea. Fractions 7-11 reveal the gel pattern kne $\alpha$-crystallin after dissociation into polypeptides

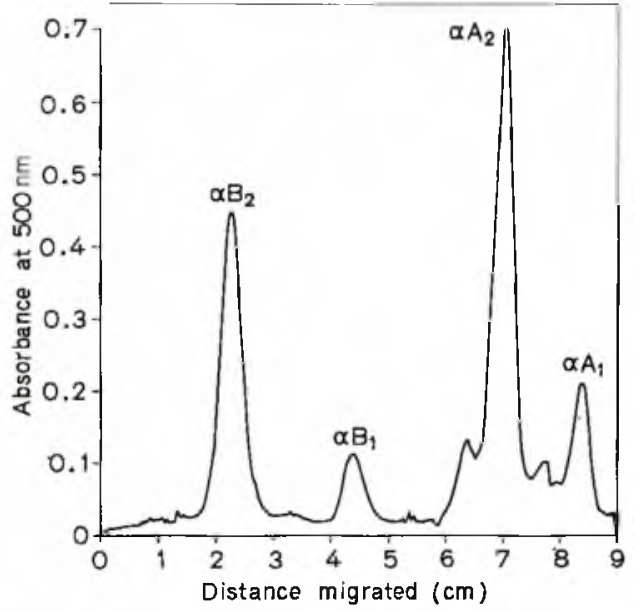

Fig.8. Typical profile of $\alpha$-crystallin in 6-M urea obtained after scanning gels 7-11 (compare Fig.7) in a Gilford recording-spectrophotometer model-240. The area under each peak was determined with a planimeter

The authors are grateful to Miss Marlies Versteeg for carrying out the amino-acid analyses and to Dr M. M. A. Sassen for his hospitality and help with the electron microscopic experiments. The present investigations have partly been carried out under auspices of the Netherlands Foundation for Chemical Research (S.O.N.) and with financial aid from the Netherlands Organization for the advancement of Pure Research (Z.W.O.).

\section{REFERENCES}

1. Bloemendal, H., Anal. Chim. Acta, 38 (1967

2. Bloemendal, H., and Schoenmakers, J. G. G 15 (1968) 6.

3. Schoenmakers, J. G. G., and Bloemendal, (London), 220 (1968) 790.

4. de Groot, K., Hoenders, H. J., Leon, A. E., a dal, H., Exp. Eye Res. 10 (1970) 71.

5. Hoenders, H. J., Schoenmakers, J. G. G., J. T., Tesser, G. I., and Bloemendal, H., $E$ 7 (1968) 291.

6. Schoenmakers, J. G. G., Gerding, J. J. T., aj dal, H., Eur. J. Biochem. 11 (1969) 472.

7. Corran, P.H., and Waley, S. G., Biochem.J. 1

8. Leon, A. E., Gerding, J. J. T., de Groot, K H. J., and Bloemendal, H., Int. J. Pro (1971) 19.

9. Bloemendal, H., Bont, W. S., Jongkind, J. F J. H., Biochim. Biophys. Acta, 82 (1964) 1

10. Bloemendal, H., and Ten Cate, G., Arch. $B$ phys. 84 (1959) 512.

11. Scheidegger, J. J., Int. Arch. Allergy, 7 (195t

12. Gerding, J. J. T., Int. J. Protein Res. 2 (1968

13. van Es, W.L., and Bont, W.S., Anal. Biochem.

14. Bloemendal, H., Electrophoresis in Blocks a Elsevier, Amsterdam 1963.

15. Schoenmakers, J. G. G., Hoenders, H. J., a] dal, H., Exp. Eye Res. 7 (1968) 172.

16. Bloemendal, H., Exp. Eye Res. 8 (1969) 227

17. van Dam, A., Thesis, Nijmegen 1967.

18. Bloemendal, H., Bont, W. S., Jongkind, J. F J. H., Exp. Eye Res. 1 (1962) 300.

19. Delcour, J., and Papaconstantinou, J., $B$ phys. Res. Commun. 41 (1970) 401.

H. Bloemendal, T. Berns, A. Zweers and H. Hc Laboratorium voor Biochemie der Universiteit Geert Groteplein Noord 21, Nijmegen, The Neth. 